\title{
Combinação da altura de desponte e do espaçamento entre plantas de tomate
}

\author{
Siegfried Mueller; Anderson Fernando Wamser \\ EPAGRI-EE de Caçador, C. Postal 591, 89500-000 Caçador-SC; simueller@epagri.sc.gov.br; afwamser@epagri.sc.gov.br
}

\section{RESUMO}

Em trabalhos a campo realizados na Epagri, Estação Experimental de Caçador (SC), durante as safras de 1998/1999, 1999/2000 e 2000/2001, estudou-se a interação entre quatro alturas de desponta (acima do $5^{\circ}, 7^{\circ}, 9^{\circ}$ e $11^{\circ}$ cachos) e quatro espaçamentos entre plantas $(0,30 ; 0,45 ; 0,60$ e $0,75 \mathrm{~m})$, de plantas de tomate cv. Diva. O espaçamento entre fileiras foi de 1,0 m para todos os tratamentos e anos estudados. O delineamento experimental foi de blocos completos ao acaso, em um fatorial $4 \times 4$, com três repetições. As plantas foram tutoradas em ' $\mathrm{V}$ ' invertido empregando-se varas de bambu (taquaruçú) como tutores. Foram avaliados a produtividade e o número de frutos total e comercial, a percentagem e a massa média de frutos comercial, a altura de plantas e o diâmetro da base do caule. O aumento do espaçamento de plantas reduziu a altura das plantas, o número e a produtividade de frutos comercial e total, porém proporcionou aumento do diâmetro do caule e da massa média dos frutos comerciais. Por sua vez, o aumento do número de cachos por planta aumentou a altura das plantas, o número e a produtividade de frutos comercial e total. Entretanto, o diâmetro do caule e a massa média dos frutos comerciais diminuíram com o aumento do número de cachos por planta.

Palavras-chave: Lycopersicon esculentum, produtividade, massa média de frutos.

\section{ABSTRACT \\ Combination of planting densities with top lopping heights of tomato plants}

Three field experiments were carried out in Caçador, Santa Catarina State, Brazil, during 1998/1999, 1999/2000 and 2000/2001 seasons to study four lopping heights of the tops (above the $5^{\text {th }}, 7^{\text {th }}$, $9^{\text {th }}$, and $11^{\text {th }}$ clusters $)$ and four-plant spacings between plants $(0.30$; $0.45 ; 0.60$, and $0.75 \mathrm{~m})$. Plant spacing between rows of tomato $\mathrm{cv}$. Diva was of $1.0 \mathrm{~m}$, in all studied treatments and years of the research. Experiments were designed in randomized blocks, with three replicates in a factorial scheme (4 $\mathrm{x} 4$ ). Plants were staked as crossed fence, using bamboo sticks as tutors. The yield, number of fruits, percentage and average weight of marketable fruits, plant height and stem base diameter were evaluated. Higher plant spacing resulted in a reduction of plant height, of the number and yield of commercial and total fruits. However, larger plant spacing provided higher average values of stem diameter and average weight of commercial fruits. In turn, the higher number of fruit clusters resulted in higher tomato plants, in the number of tomato fruits and yield of commercial and total fruits. However, more clusters in a plant reduced the stem diameter and the average weight of the commercial fruits.

Keywords: Lycopersicon esculentum, yield, average fruit weight.

\section{(Recebido para publicação em 14 de agosto de 2007; aceito em 20 de janeiro de 2009) (Received in August 14, 2007; accepted in January 20, 2009)}

$\mathrm{O}_{\mathrm{p}}$ tomate foi introduzido no Brasil a partir de 1940, provavelmente por imigrantes europeus, e atualmente é uma das hortaliças mais cultivadas neste país. No Brasil são plantados, anualmente, em torno de 60 mil ha de tomate cuja produtividade é de aproximadamente 57 t ha ${ }^{-1}$ o que resulta numa produção de 3.450.000 t por ano (ICEPA, 2004).

O estado de Santa Catarina inserese no contexto nacional como exportador de tomate para os grandes e exigentes centros de abastecimento e consumo do país (Silva Júnior et al., 1992). Em Caçador (SC), a cultura do tomate representa grande importância socioeconômica, destacando-se esta como a principal cultura agrícola. Esta é considerada a maior região do estado e há cerca de quatro mil pessoas em 600 propriedades rurais envolvidas com a cultura do tomate, sendo que destas, $60 \%$ trabalha em empresas de natureza familiar e $40 \%$ em empresas de médio a grande porte ou por parceria. Embora os produtores de tomate alcancem boa produtividade na região, eles necessitam de conhecimentos atualizados para melhor aproveitamento dos recursos naturais renováveis e não renováveis.

O espaçamento de plantio é um dos itens importantes na cadeia de técnicas de cultivo de tomate, podendo interferir no ciclo da planta, no controle de doenças, na qualidade e na quantidade de frutos colhidos (Fery \& Janick, 1970; Nichols, 1987).

Conforme Silva Júnior et al. (1992) e Hooda et al. (2001) as altas densidades no cultivo de tomate favorecem a disseminação das principais doenças e dos distúrbios fisiológicos. Uma das consequências desta prática é o estiolamento do caule devido ao aumento do comprimento dos internódios (Adpawar et al., 2000). Assim, a maior densidade de plantas de tomate induz ao aumento da altura das plantas ocasionado pela busca de luz (Streck et al., 1996).

A produtividade do tomate é função do número de plantas por unidade de área, do número de frutos colhidos por planta e da massa média dos frutos (Fery \& Janick, 1970). O decréscimo da produção é ocasionado pela concorrência por luz, água e nutrientes, assim como pelo autosombreamento e pela diminuição da taxa fotossintética líquida (Larcher, 1995).

Os rendimentos de tomate aumentam com espaçamentos mais próximos, enquanto a produtividade por planta e a massa média dos frutos diminuem (Fery \& Janick, 1970; Campos et al.,1987; Moccia \& Katcherian, 1997; Adpawar et al., 2000; Ahmed et al., 2001; Hooda et al., 2001). Também diminuem com o aumento das densidades de plantio de tomate, o número dos frutos por planta (Adpawar et al., 2000; Ahmed et al., 
2001; Dobromilska, 2002) e os sólidos solúveis totais (SST) (Adpawar et al., 2000; Ahmed et al., 2001). Os espaçamentos de plantio mais densos de tomate ainda proporcionam um florescimento (Adpawar et al., 2000) e a colheita mais precoces (Adpawar et al., 2000; Hooda et al., 2001). Por outro lado Streck et al. (1996) encontraram que o tempo do transplantio de tomate à primeira florada e a da primeira florada à primeira colheita, não foi influenciado pela densidade de plantas.

Fery \& Janick (1970) e Campos et al. (1987) salientam que a densidade de plantio de tomate, a ser recomendada, varia de acordo com a cultivar e o ambiente, pois há uma variabilidade de tipos e/ou arquiteturas de planta entre as cultivares plantadas.

Segundo Silva Júnior et al. (1992), uma das alternativas para simplificar o tutoramento do tomateiro é através da redução da altura da planta, com a remoção do broto terminal. Esta técnica não só permite uma economia considerável de mão-de-obra, como também aumenta a eficiência no controle de pragas e doenças, reduz o ciclo cultural, melhora a distribuição de luz na cultura e incrementa a qualidade do fruto.

Conforme Fisher (1977), a poda apical das plantas interrompe o seu crescimento, diminui o ciclo da cultura e a altura das plantas, o que por sua vez facilita a execução dos tratos culturais, melhora a eficiência no controle das doenças, podendo, melhorar a qualidade do produto. Por outro lado, a poda apical da haste tem como grande inconveniente a redução do número de rácimos e, consequentemente, de frutos por planta além de induzir uma maior ocorrência de frutos rachados. Silva Júnior et al. (1992) verificaram que a poda apical diminui o ciclo da cultura, porém a ocorrência de doenças (alternária e requeima) potencializa o efeito da poda em acelerar a maturação dos frutos.

Conforme Campos et al. (1987), a poda reduz o ciclo, o porte, o número de folhas e a área foliar da planta. A poda, ao reduzir o ciclo das plantas pela limitação do estádio reprodutivo também contribui para a menor ocorrência de doenças e pragas, as quais ocorrem com maior intensidade no final do ciclo da cultura, quando as plantas apresentam-se menos vigorosas e mais suscetíveis.

Silva Júnior et al. (1992) verificaram que a poda apical, sob alta densidade de plantio, poderá ser prática viável em regiões e períodos de temperaturas amenas e de pouca pluviosidade, ou sob condições protegidas.

Silva (1994) constatou que a menor produção de frutos por planta, devido à poda apical, pode ser compensada pelo aumento do estande e, devido à maior proporção de frutos maiores, o que permite a obtenção de elevada produtividade (185 t/ha).

O objetivo deste trabalho foi verificar a melhor combinação entre espaçamento de plantio e altura de desponte de plantas de tomate para a obtenção de alta produtividade e qualidade de frutos.

\section{MATERIAL E MÉTODOS}

Três experimentos foram executados em condições de campo durante as safras de 1998/99, 1999/2000 e 2000/01, na Epagri, Estação Experimental de Caçador (2646'32' S; 5100'50'"W; $960 \mathrm{~m}$ de altitude). $\mathrm{O}$ clima da região é temperado, constantemente úmido, do tipo $\mathrm{Cfb}$, conforme classificação de Köppen (Pandolfo et al., 2002). O solo do local é classificado como Latossolo Bruno distrófico típico (Embrapa, 1999).

O delineamento experimental foi de blocos completos ao acaso, com os tratamentos analisados em esquema fatorial 4 x 4, com três repetições. Os tratamentos consistiram da combinação de quatro alturas de desponte, três folhas acima do $5^{\circ}, 7^{\circ}, 9^{\circ}$ e $11^{\circ}$ cacho, e de quatro espaçamentos entre plantas na linha, 0,$30 ; 0,45 ; 0,60$ e $0,75 \mathrm{~m}$, totalizando 16 tratamentos. A cultivar de tomate "Diva" foi plantada no espaçamento entre fileiras de 1,0 m, para todos os tratamentos e anos estudados. Cada parcela era composta por duas fileiras com 3,6 m de comprimento, para os espaçamentos entre plantas de 0,30; 0,45 e 0,60 m e de 3,75 m de comprimento, para o espaçamento de $0,75 \mathrm{~m}$; o que resultou em 7,2 $\mathrm{m}^{2}$ e $7,5 \mathrm{~m}^{2}$ de área total, respectivamente. Foram colhidas em cada tratamento/parcela 16; 10; 8 e 6 plantas nos espaçamentos entre plantas de 0,$30 ; 0,45,0,60$ e $0,75 \mathrm{~m}$, respectivamente, correspondendo às respectivas áreas úteis de 4,8; 4,5; 4,8 e $4,5 \mathrm{~m}^{2}$.

As mudas foram produzidas no sistema float, em bandejas com 128 células, preenchidas com substrato comercial Plantimax HT®, as quais foram postas em piscinas dentro de estufa coberta com filme plástico. Os plantios foram feitos quatro semanas após a semeadura, em 05/11/98, 22/11/99 e 14/11/00. As colheitas foram realizadas de 20/01/99 a 12/03/99, em número de 11, na safra 1998/ 99; de 04/02/00 a 22/03/00, em número de 11, na safra 1999/2000; e 01/02/01 a $12 / 03 / 01$, em número de 9 , na safra de 2000/2001.

O solo foi preparado com uma aração e uma gradagem. A adubação de plantio foi realizada duas semanas antes do plantio nos sulcos, utilizando $10 \mathrm{t} \mathrm{ha}^{-1}$ de esterco de frango (com quatro crias), $80 \mathrm{~kg} \mathrm{ha}^{-1}$ de $\mathrm{N}$ (nitrato de cálcio), $320 \mathrm{~kg}$ ha $^{-1}$ de $\mathrm{P}_{2} \mathrm{O}_{5}$ (superfosfato triplo), $60 \mathrm{~kg}$ $\mathrm{ha}^{-1}$ de $\mathrm{K}_{2} \mathrm{O}$ (cloreto de potássio) e $30 \mathrm{~kg}$ ha $^{-1}$ de B (Bórax). As doses dos adubos químicos, exceto de Bórax, foram parceladas em duas aplicações: 2/3 da dose aproximadamente no plantio e $1 / 3 \mathrm{da}$ dose aproximadamente 14 dias após o plantio, no ato da amontoa. $\mathrm{O}$ método de tutoramento foi o "V" invertido com utilização de varas de bambu (taquaruçú) como tutores. A irrigação das plantas e a adubação de cobertura foram feitas através de fertirrigação. A adubação de cobertura foi feita semanalmente, totalizando $250 \mathrm{~kg} \mathrm{ha}^{-1}$ de $\mathrm{Ne} 200 \mathrm{~kg} \mathrm{ha}^{-1} \mathrm{de}$ $\mathrm{K}_{2} \mathrm{O}$.

O controle fitossanitário das doenças e das pragas foi realizado sistematicamente a cada semana ou após a ocorrência de chuva, com os fungicidas Clorotalonil, Oxicloreto de Cobre, Iprodione, Mancozeb, Metalaxil e Captan e com os inseticidas Acephate, Fenitrothion e Deltamethrine. As plantas daninhas foram controladas com capinas manuais. Demais práticas de manejo foram realizadas conforme as Normas técnicas para o tomate tutorado na região do Alto Vale do Rio do Peixe (EPAGRI, 1997).

Foram avaliados o diâmetro do caule no final da colheita, a aproximadamente três centímetros do solo, nas safras 1998/1999 e 1999/2000; a altura de plan- 
tas no final da colheita, na safra 1999/ 2000 e a produtividade e número de frutos comercial e total, percentagem e massa média de frutos comerciais, nas safras 1998/1999, 1999/2000 e 2000/2001.

As variáveis estudadas foram submetidas à análise de variância pelo teste de $\mathrm{F}$ ao nível de $5 \%$ de probabilidade e, havendo diferença significativa entre os tratamentos, suas médias foram submetidas à análise de regressão polinomial. As análises estatísticas foram realizadas através do programa SISVAR 5.0 (Ferreira, 2000).

\section{RESULTADOS E DISCUSSÃO}

Na safra 1999/2000, houve ajuste linear altamente significativo para altura de plantas em função do espaçamento entre plantas e da altura de desponte (Tabela 1). A altura média de plantas diminuiu linearmente com o aumento do espaçamento entre plantas. Resultados
Tabela 1. Altura de plantas e diâmetro do caule de tomate cv. "Diva", em função do espaçamento entre plantas e do número de cachos por planta (plant height and stem diameter of tomato cv. "Diva", in relation to plant spacing in the row and number of clusters per plant). Caçador, EPAGRI, 1998 a 2000.

\begin{tabular}{|c|c|c|c|}
\hline \multirow{2}{*}{ Nível do fator } & \multirow{2}{*}{$\begin{array}{c}\text { Altura de plantas (m) } \\
\text { Safra } 1999 / 2000\end{array}$} & \multicolumn{2}{|c|}{ Diâmetro do caule (mm) } \\
\hline & & Safra 1998/1999 & Safra $1999 / 2000$ \\
\hline \multicolumn{4}{|c|}{ Espaçamento entre plantas $(\mathrm{m})$} \\
\hline 0,30 & 1,72 & 14,6 & 20,6 \\
\hline 0,45 & 1,58 & 16,1 & 21,8 \\
\hline 0,60 & 1,52 & 17,6 & 22,5 \\
\hline 0,75 & 1,42 & 18,2 & 23,4 \\
\hline Regressão & $Y=1,88-0,006 X$ & $Y=12,3+0,08 X$ & $Y=18,8+0,06 X$ \\
\hline $\mathrm{R}^{2}$ & $0,968^{* *}$ & $0,970^{* *}$ & $0,988^{* *}$ \\
\hline \multicolumn{4}{|c|}{ Número de cachos por planta } \\
\hline 5 & 1,18 & 17,4 & 22,4 \\
\hline 7 & 1,44 & 16,7 & 22,3 \\
\hline 9 & 1,61 & 16,5 & 21,5 \\
\hline 11 & 2,01 & 15,9 & 22,1 \\
\hline Regressão & $Y=0,50+0,132 X$ & $Y=18,5-0,24 X$ & ns \\
\hline $\mathrm{R}^{2}$ & $0,971^{* *}$ & $0,964^{* *}$ & \\
\hline
\end{tabular}

**Significativo a $1 \%$ de probabilidade; ns: Não significativo. (**significant at $1 \%$ probability; ns: not significant).

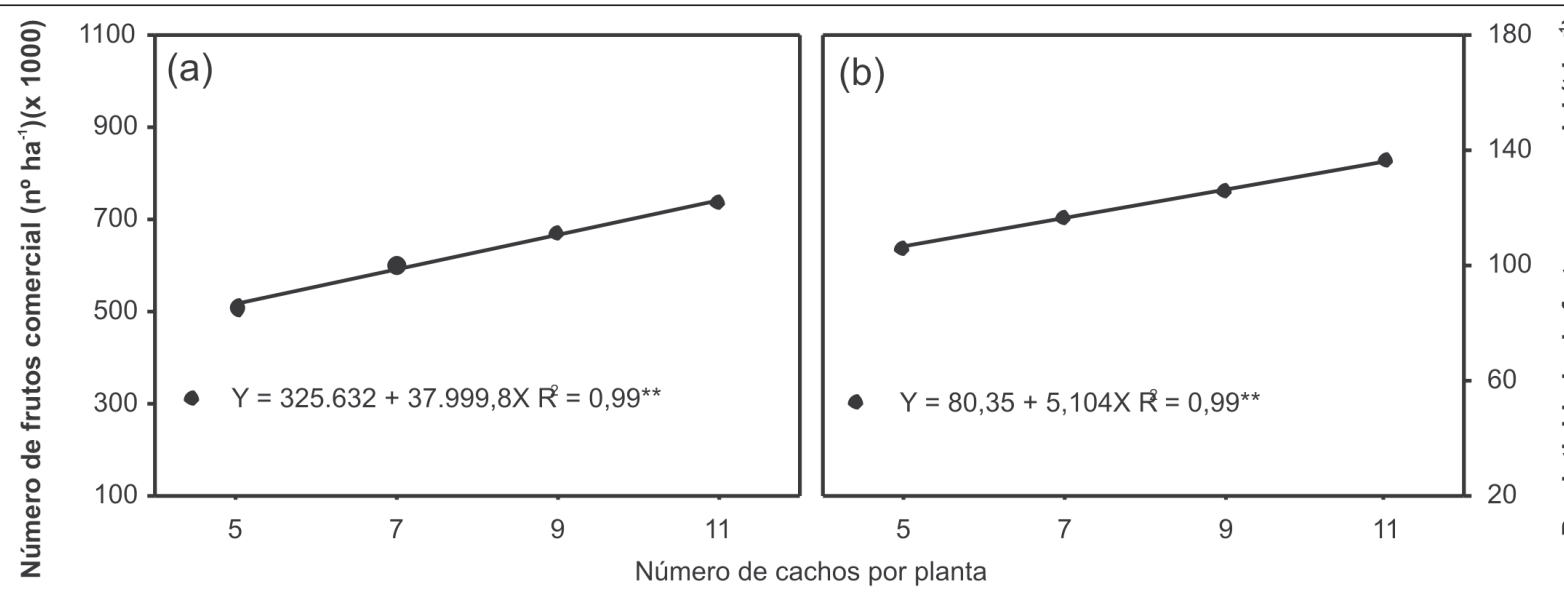

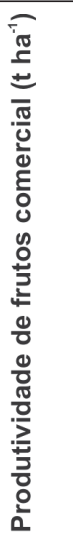
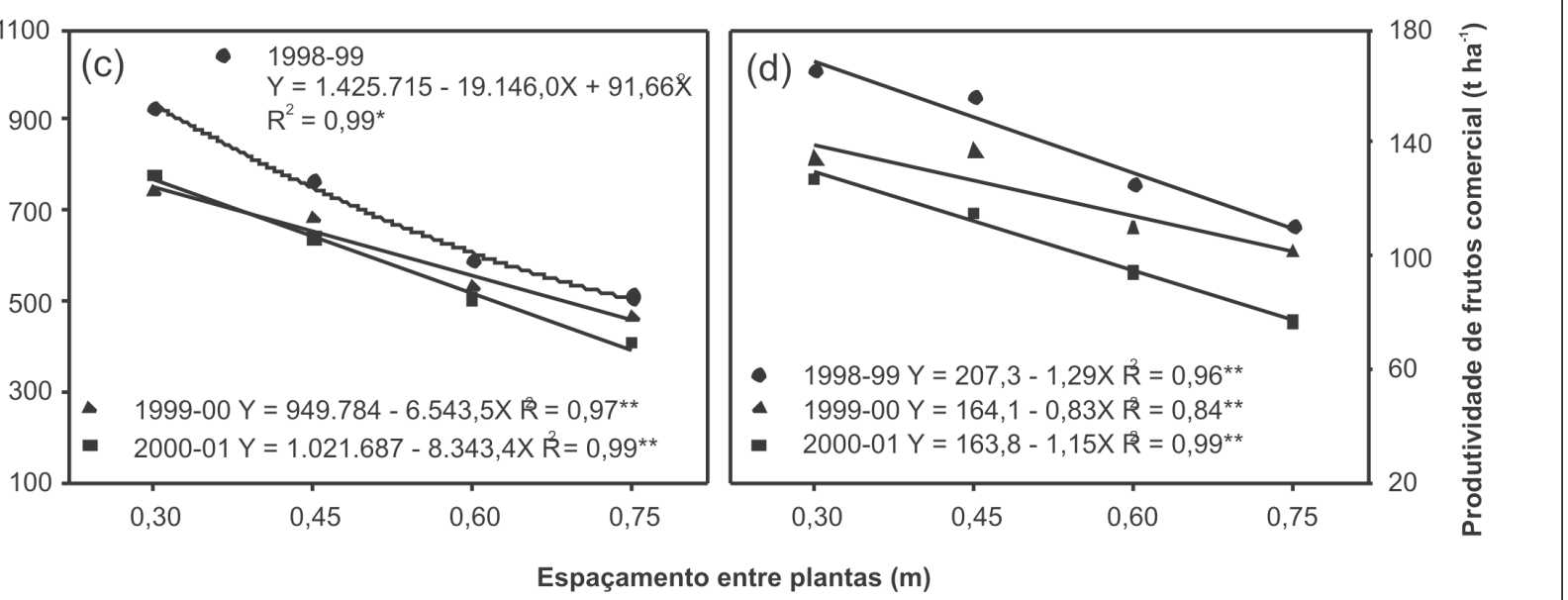

Figura 1. Número e produtividade comercial de frutos de tomate cv. "Diva" em função do número de cachos por planta e do espaçamento entre plantas (number and yield of commercial fruits of tomato cv. "Diva" in relation to number of clusters per plant and plant spacing in the row). Caçador, EPAGRI, 1998 a 2001. 
semelhantes foram observados por Seleguini et al. (2006). Segundo Silva Junior (1992) e Streck et al. (1996), a maior densidade de plantas causa maior altura de plantas devido ao aumento do comprimento dos internódios ocasionado pela busca mais intensa da luz. Como era de se esperar, a altura de plantas diminuiu linearmente com a diminuição do número de cachos por planta, o que é concordante com Fisher (1977), ao afirmar que a poda apical interrompe o crescimento da planta, diminuindo a sua altura.

Para o diâmetro de caule houve ajuste linear altamente significativo para os dois fatores estudados na safra de 1998/ 99, e somente para o fator espaçamento entre plantas na safra de 1999/2000 (Tabela 1). $\mathrm{O}$ diâmetro de caule aumentou com o aumento do espaçamento entre plantas e diminuiu com o aumento do número de cachos por planta. Assim, deduz-se que o aumento dos espaçamentos de plantio e/ou a diminuição da altura das plantas fez com que as plantas de tomate aumentassem suas reservas nos caules.

Para as variáveis a seguir abordadas foi possível fazer a análise de variância conjunta para as três safras estudadas.

Para as variáveis número e produtividade de frutos comerciais observouse que houve diferença para a altura de desponte e também para a interação espaçamento entre plantas e ano. O número e a produtividade de frutos comerciais aumentaram linearmente em resposta ao aumento da altura de desponte (Figura 1a e 1b). Para o fator espaçamento entre plantas (Figura 1c e 1d) observa-se que, embora houvesse interação entre os anos estudados, o número e a produtividade de frutos comerciais por hectare diminuiu em resposta ao aumento do espaçamento entre plantas nos três anos.

Para o número de frutos total, observou-se que houve efeito significativo para a interação espaçamento entre plantas e altura de desponte. Nas condições em que foram realizados os experimentos, houve ajuste linear altamente significativo para o desponte acima do $7^{\circ}$ e $11^{\circ}$ cacho, porém para os despontes acima do $5^{\circ}$ e $9^{\circ}$ cacho houve ajuste quadrático significativo (Figura 2a). Entretanto, para todas as alturas de desponte, o número de frutos total diminuiu com o aumento do espaçamento entre plantas. Já para a variável produtividade de frutos total (Fi-
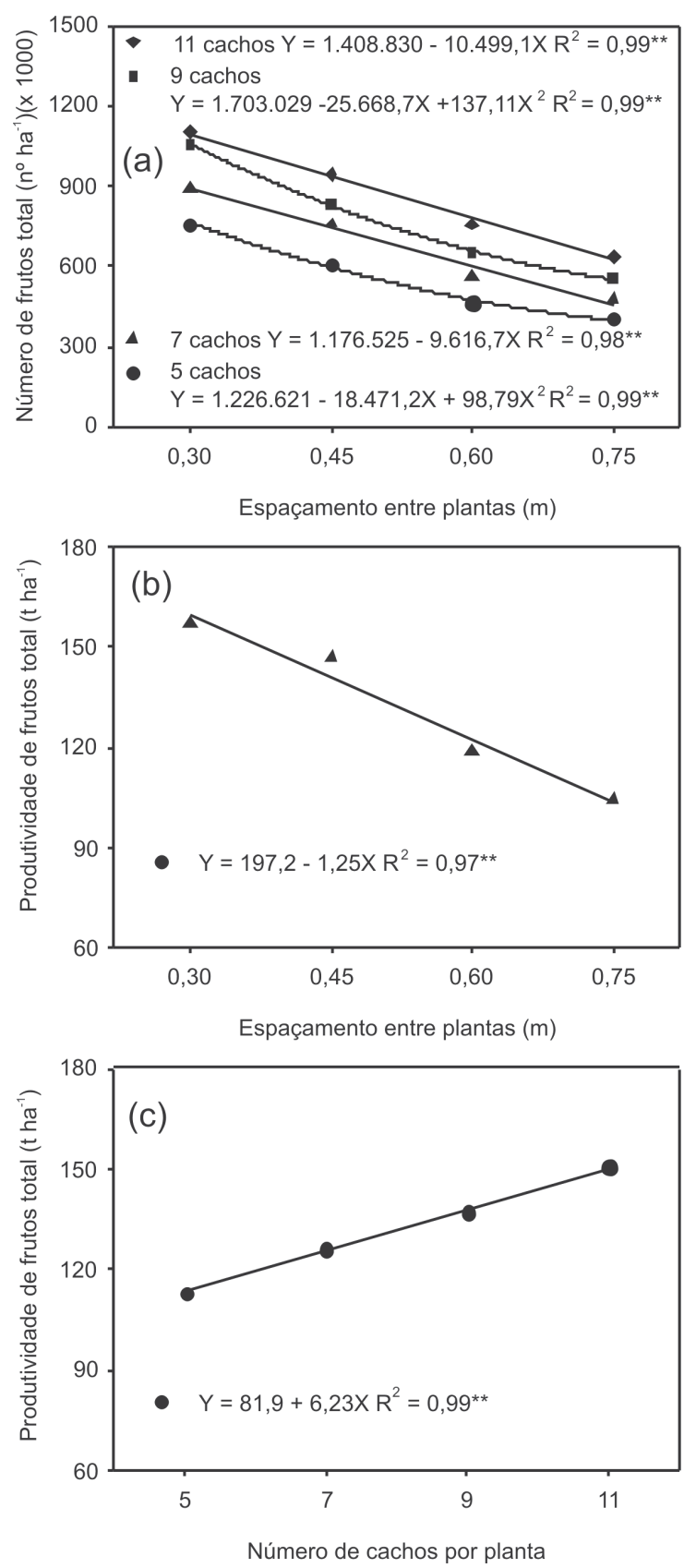

Figura 2. Número e produtividade total de frutos de tomate cv. "Diva" em função do espaçamento entre plantas e do número de cachos por planta (total number of fruits and yield of tomato cv. "Diva" in relation to plant spacing in the row and number of clusters per plant). Caçador, EPAGRI, 1998 a 2001

gura $2 b$ e $2 c$ ) houve efeito significativo para os fatores espaçamento de plantio e altura de desponte. A produtividade de frutos total diminuiu com o aumento do espaçamento entre plantas, porém aumentou com o aumento da altura de desponte das plantas.

Analisando os resultados para número e produtividade comercial e total de frutos, em função do espaçamento entre plantas e da altura de desponte das plantas de tomate da cv. "Diva", verifica-se que quanto maiores os espaçamentos entre plantas, menores foram os valores observados. Resultados semelhantes foram encontrados por Moccia \& Katcherian (1997), Adpawar et al. (2000), Hooda et al. (2001) e Seleguini et al. (2006) que constataram que a produtividade de tomate aumentou com a diminuição do espaçamento de plantio. No entanto, estes resultados 

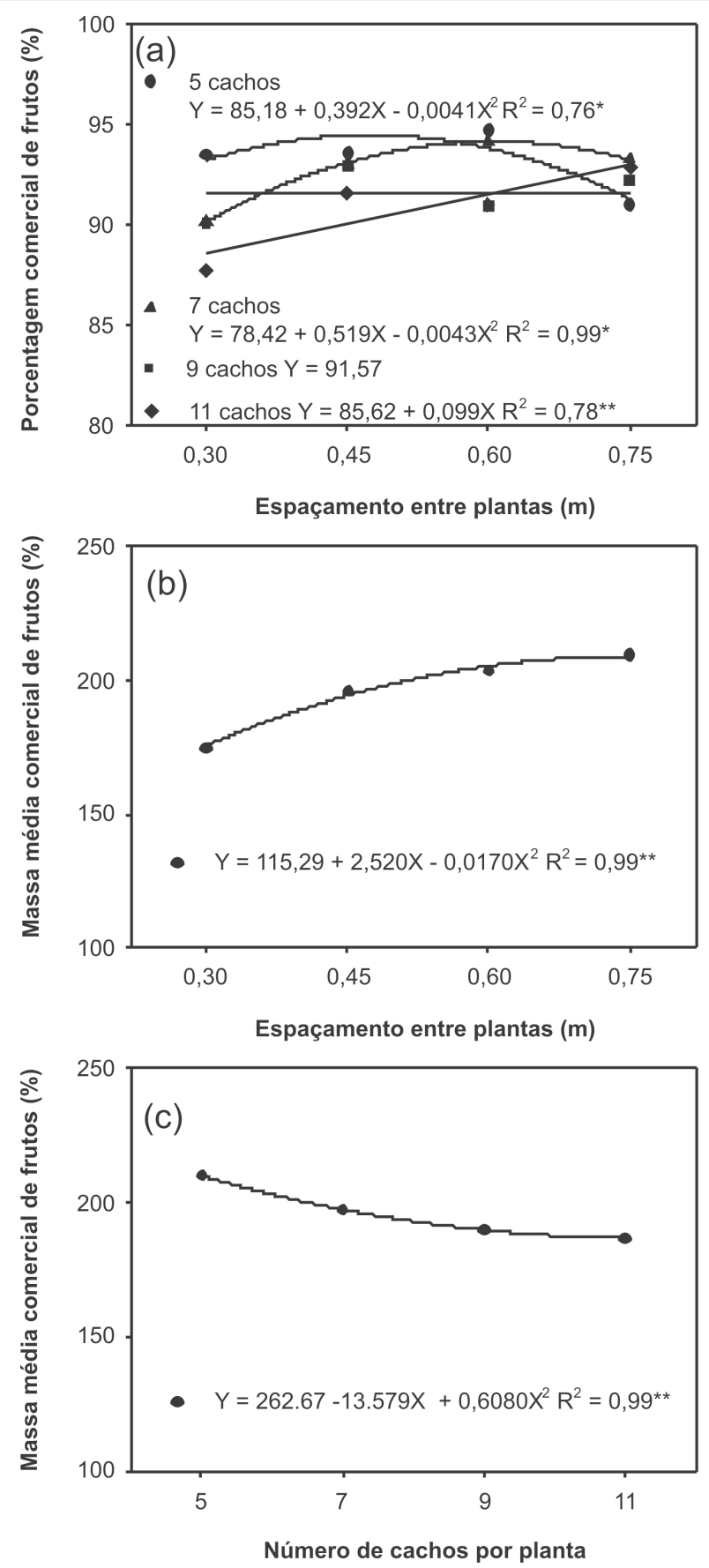

Figura 3. Percentagem e massa média comercial de frutos de tomate cv. "Diva" em função do espaçamento entre plantas e do número de cachos por planta (percentage and mean weight of commercial fruits of tomato cv. "Diva" in relation to plant spacing in the row and number of clusters per). Caçador, EPAGRI, 1998 a 2001.

são discordantes de Sharma et al. (2001), que verificaram maior produtividade de frutos no maior espaçamento entre plantas $(0,60 \mathrm{~m})$. O efeito do espaçamento entre plantas pode ser influenciado por outros fatores como a adubação nitrogenada e cultivar utilizada, principalmente no aparecimento de doenças fúngicas e bacterianas que, consequentemente, influenciam a produtividade de tomate.

Em relação à poda apical, pode-se verificar que o número e a produtividade de frutos totais e comerciais aumentaram com o aumento da altura de desponte e isto caracteriza que, quanto maior o número de cachos por planta, maior será a sua produtividade. Segundo Fisher
(1977) a poda apical das plantas tem como grande inconveniente a redução do número de cachos e, consequentemente, redução de frutos por planta.

Para a percentagem de frutos comerciais houve interação significativa entre o espaçamento entre plantas e a altura de desponte e entre o ano e espaçamento entre plantas (Figuras 3a a 3c). O espaçamento entre plantas influiu na percentagem de frutos comerciais da seguinte forma: houve ajuste quadrático altamente significativo para o desponte acima do $5^{\circ}$ e $7^{\circ}$ cacho, e linear positivo quando o desponte foi realizado após o $11^{\circ}$ cacho. Porém, para o desponte acima do $9^{\circ}$ cacho a percentagem de frutos comerciais não foi influenciada pelos espaçamentos (Figura 3a). Os ajustes das regressões mostram que com a diminuição do número de cachos por planta, a maior porcentagem de frutos comerciais ocorre nos menores espaçamentos entre plantas.

Para a massa média de frutos comerciais houve efeito para os fatores espaçamento entre plantas e altura de desponte. A massa média de frutos comerciais aumentou de modo quadrático em resposta ao aumento do espaçamento entre plantas e isto mostra que quanto menor a competição entre plantas de tomate, maior é o desenvolvimento dos frutos até certo limite (Figura 3b). Os resultados dos espaçamentos de plantio obtidos neste trabalho são concordantes com Fery \& Janick (1970), Moccia \& Katcherian (1997), Adpawar et al. (2000) e Hooda et al. (2001), os quais também observaram que a massa média dos frutos de tomate aumentou com o aumento dos espaçamentos utilizados.

A massa média de frutos comerciais diminuiu de modo quadrático em resposta ao aumento da altura de desponte (Figura 3c). Isto se deve, em parte, à maior competição entre frutos pelos fotoassimilados. Por outro lado, o crescimento em altura das hastes também demanda por fotoassimilados, aumentando a competição entre frutos e hastes. Estes resultados da poda apical são concordantes com Silva (1994), o qual relata que esta poda proporciona aumentos na proporção de frutos maiores.

Diante dos resultados obtidos conclui-se que o efeito do espaçamento en- 
tre plantas sobre a produção de frutos de tomate independe do número de cachos por planta. As maiores produtividades são obtidas com o menor espaçamento e a maior altura de desponta. Os aumentos dos espaçamentos de plantio de tomate resultam em redução da altura das plantas, do número e produtividade de frutos comercial e total, porém proporcionam aumento nos valores médios de diâmetro do caule e do peso médio dos frutos comerciais. Por sua vez, os aumentos do número de cachos por planta resultam em aumentos na altura das plantas de tomate e no número e produtividade de frutos comercial e total, entretanto conferem a redução do diâmetro do caule e da massa dos frutos comerciais.

\section{REFERÊNCIAS}

ADPAWAR RM; KALE PB; KALE VS; GUPTA NS; BHARAD SG. 2000. Effect of spacing and staking on growth, yield and quality of tomato var. Dhanshree. Annals of Plant Physiology 14: 26-31.

AHMED SA; EL-SUOUD MRA; METWALLY GM. 2001. Effect of plant density and some weed control treatments on tomato and its associated weeds. Bulletin of the National Research 26: 493-510.

CAMPOS JP; BELFORT CC; GALVÃO VD; FONTES PCR. 1987. Efeito da poda da haste e da população de plantas sobre a produção do tomateiro. Revista Ceres 34: 198-208.
DOBROMILSKA R. 2002. The effect of plant spacing on the yield and storability of three cultivars of small-sized tomato. Folia Horticulturae 14: 37-44.

EMBRAPA. Centro Nacional de Pesquisas de Solos. 1999. Sistema brasileiro de classificação de solos. Rio de Janeiro: Embrapa Solos. 412p.

EPAGRI. 1997. Normas técnicas para o tomateiro tutorado na região do Alto Vale do Rio do Peixe. Florianópolis: Epagri. 60p. (EPAGRI. Sistemas de Produção, 27).

FERREIRA DF. 2000. Análises estatísticas por meio do Sisvar para Windows versão 4.0. In... REUNIÃO ANUAL DA REGIÃO BRASILEIRA DA SOCIEDADE INTERNACIONAL DE BIOMETRIA, 45. Anais... São Carlos: UFSCar. p.255-258.

FERY RL; JANICK J. 1970. Effect of planting pattern and population pressure on the yield response of tomato. HortScience 5: 443-444.

FISHER KJ. 1977. Competition effects between fruit trusses of the tomato plant. Scientia Horticulturae 7: 37-42.

HOODA RS; SINGH J; MALIK YS; BATRA VK. 2001. Effect of planting geometry on fruiting behavior of direct seeded tomato. Haryana Journal of Horticultural Sciences 30: 111-113.

INSTITUTO DE PLANEJAMENTO E ECONOMIA AGRÍCOLA DE SANTA CATARINA (ICEPA). 2004. Sintese anual da agricultura de Santa Catarina, 20032004. Florianópolis: Instituto Cepa/SC. p.121-128.

LARCHER W. 1995. Physiological plant ecology. Berlin: Springer. 448p.

MOCCIA S; KATCHERIAN F. 1997. Efecto de la densidad sobre los componentes del rendimiento de tomate "cherry". Horticultura Argentina 16: 5-10.
NICHOLS MA. 1987. Plant spacing: key to greater process vegetable crop productivity. Acta Horticultural 220: 223-228.

PANDOLFO C; BRAGA HJ; SILVA JÚNIOR VP; MASSIGNAM AM; PEREIRA ES; THOMÉ VMR. 2002. Atlas climatológico digital do Estado de Santa Catarina. Florianópolis: Epagri.(CD-ROM).

SHARMA DK; CHAUDHARY DR; VERMA TS. 2001. Growth and seed yield of tomato (Lycopersicon esculentum Mill) cv. Roma as influenced by levels of nitrogen and plant spacing. Journal of Horticultural Sciences 30: $95-96$.

SELEGUINI A; SENO S; FARIA JÚNIOR MJA. 2006. Espaçamento entre plantas e número de rácimos para tomateiro em ambiente protegido. Acta Scientiarum Agronomy 28: 359-363.

SILVA JÚNIOR A; MÜLLER JJV; PRANDO HF. 1992. Poda de alta densidade de plantio de tomate. Agropecuária Catarinense 5: 57-61.

SILVA EC. 1994. Efeito de doses de nitrogênio (nitrocálcio) e potássio (cloreto de potásssio) na produção e em algumas características qualitativas dos frutos de tomateiro (Lycopersicon esculentum Mill), cultivar Santa Clara, podado e adensado. Lavras: Escola Superior de Lavras. 92p (Tese mestrado).

STRECK NA; BURIOL GA; SCHNEIDER FM. 1996. Efeito da densidade de plantas sobre a produtividade do tomateiro cultivado em estufa de plástico. Pesquisa Agropecuária Brasileira 31: 105-112. 